\title{
ORIGINAL
}

\section{Randomised evaluation of active control of temperature versus ordinary temperature management (REACTOR) trial}

Paul J. Young ${ }^{1,2^{*}}$ (D, Michael J. Bailey ${ }^{3}$, Frances Bass ${ }^{4,5}$, Richard W. Beasley ${ }^{2}$, Ross C. Freebairn ${ }^{2,6}$, Naomi E. Hammond ${ }^{4,5}$, Frank M. P. van Haren ${ }^{7,8,9}$, Meg L. Harward ${ }^{4}$, Seton J. Henderson ${ }^{10}$, Diane M. Mackle ${ }^{2}$, Colin J. McArthur 2,11, Shay P. McGuinness, 2,12, John A. Myburgh ${ }^{4}$, Manoj K. Saxena ${ }^{4,13}$, Anne M. Turner ${ }^{2}$, Steve A. R. Webb3 $3,14,15$, Rinaldo Bellomo ${ }^{3,16}$, the REACTOR investigators and ANZICS Clinical Trials Group

(c) 2019 Springer-Verlag GmbH Germany, part of Springer Nature

\begin{abstract}
Purpose: It is unknown whether protocols targeting systematic prevention and treatment of fever achieve lower mean body temperature than usual care in intensive care unit (ICU) patients. The objective of the Randomised Evaluation of Active Control of temperature vs. ORdinary temperature management trial was to confirm the feasibility of such a protocol with a view to conducting a larger trial.

Methods: We randomly assigned 184 adults without acute brain pathologies who had a fever in the previous $12 \mathrm{~h}$, and were expected to be ventilated beyond the calendar day after recruitment, to systematic prevention and treatment of fever or usual care. The primary outcome was mean body temperature in the ICU within 7 days of randomisation. Secondary outcomes included in-hospital mortality, ICU-free days and survival time censored at hospital discharge.

Results: Compared with usual temperature management, active management significantly reduced mean temperature. In both groups, fever generally abated within $72 \mathrm{~h}$. The mean temperature difference between groups was greatest in the first $48 \mathrm{~h}$, when it was generally in the order of $0.5^{\circ} \mathrm{C}$. Overall, 23 of 89 patients assigned to active management (25.8\%) and 23 of 89 patients assigned to usual management (25.8\%) died in hospital (odds ratio 1.0, 95\% Cl $0.51-1.96, P=1.0)$. There were no statistically significant differences between groups in ICU-free days or survival to day
\end{abstract} 90.

Conclusions: Active temperature management reduced body temperature compared with usual care; however, fever abated rapidly, even in patients assigned to usual care, and the magnitude of temperature separation was small.

Trial registration: Australian and New Zealand Clinical Trials Registry Number, ACTRN12616001285448

Keywords: Fever, Infection, Sepsis, Antipyresis, Cooling, Paracetamol

\footnotetext{
*Correspondence: paul.young@ccdhb.org.nz

${ }^{1}$ Intensive Care Unit, Wellington Regional Hospital, Wellington, New Zealand
}

Full author information is available at the end of the article

\section{县 Springer}




\section{Introduction}

Intensive Care Unit (ICU) patients with a range of critical illnesses including trauma, infection, acute myocardial infarction, and pancreatitis develop fever [1-3], which increases metabolic demand $[4,5]$. Such increased metabolic demand has potentially deleterious physiological consequences including increased oxygen consumption and cardiac work [5]. One potential method to reduce these physiological demands is to systematically prevent and treat fever [6]. Early fever in the ICU is associated with increased mortality risk in patients without infections [7]. Among patients with infections, after adjustment for illness severity, the presence of fever is associated with reduced mortality risk [7]. However, in febrile mechanically ventilated patients with septic shock who are sedated, data from the SEPSIS-COOL study suggest that systematic cooling to normothermia may reduce early mortality [8].

A recent individual patient data (IPD) meta-analysis showed no overall mortality difference between more active versus less active temperature management [9]. However, there was significant heterogeneity in treatment effects on ICU and hospital length of stay in subgroups based on the receipt of organ support, and it was reported that more active fever management appeared to increase length of stay in patients who died in ICU, and to reduce length of stay in patients who survived ICU [9]. As point estimates for the effect of active fever management on ICU mortality encompassed potentially clinically important effects, further clinical trials are justified, particularly in patients with limited physiological reserves.

As clinicians are generally tolerant of relatively high body temperature in ICU patients without acute brain pathologies [10], there is potential for a systematic approach to prevention and treatment of fever to reduce fever burden compared to usual care in this population in particular. Existing evidence suggests that body temperature can be manipulated in ICU patients with medicines $[11,12]$ and physical cooling devices [8]; however, it is not known whether a systematic approach to prevention and treatment of fever can achieve a lower mean body temperature than usual care. If a systematic approach to temperature control reduces mean body temperature, it is plausible that this approach might improve clinical outcomes for ICU patients with high illness acuity [13] such as those who are deeply sedated and anticipated to require relatively prolonged mechanical ventilation.

Being certain that systematic fever prophylaxis and active temperature management actually reduce body temperature compared with usual care is a pre-requisite to undertaking a larger phase trial. Accordingly, we

\section{Take-home message}

Although febrile critically ill patients receiving systematic prevention and treatment of fever have lower heart rates than patients who receive usual temperature management, other physiological parameters are similar and fever typically abates rapidly irrespective of how aggressively fever is treated. Moreover, in-hospital mortality, ICU length of stay, hospital length of stay, ICU-free days, ventilatorfree days, vasopressor-free days, and receipt of renal replacement therapy are all similar by treatment group.

conducted the Randomised Evaluation of Active Control of Temperature vs. ORdinary temperature management (REACTOR) trial to test the hypothesis that active control of temperature would reduce body temperature compared with usual care. We also sought to better understand how treatments would differ for patients assigned to active control of temperature compared with usual care and to establish the recruitment rate.

\section{Methods \\ Trial design}

We conducted a 184-participant multicentre, prospective parallel group, phase 2, single-blinded, feasibility randomised clinical trial. The management committee designed the trial, which was endorsed by the Australian and New Zealand Intensive Care Society Clinical Trial Group. The Medical Research Institute of New Zealand (Wellington, New Zealand) and the George Institute for Global Health (Sydney, Australia) managed the project and monitored data quality. An independent data safety and monitoring committee oversaw the trial and reviewed adverse event reports. No interim analyses were conducted.

The protocol, which was reported before enrolment was completed [14], was approved by the Health Research Ethics Committee responsible for each participating institution. Written informed consent for enrolment, or consent to continue and to use patient data, was obtained from each patient or from a legal surrogate. Where a patient died before consent to continue could be obtained, data were included if allowed by local regulations and approved by the relevant ethics committee.

\section{Patients}

Mechanically ventilated patients aged 18 years or older who were: (1) expected to be ventilated beyond the calendar day after randomisation; (2) had a documented fever, defined as a body temperature of $37.8{ }^{\circ} \mathrm{C}$ or more, in the previous $12 \mathrm{~h}$; and (3) were deeply sedated with no response to voice were eligible for inclusion. Patients with acute brain pathologies were excluded. A full list of exclusion criteria is provided in the Supplementary 
Appendix. Some minor changes to the eligibility criteria were made during the conduct of the trial. The timing and rationale for each of these changes are described in the ESM (Supplementary Methods). We anticipated that we would be able to enrol 1.5 patients per site per month.

\section{Randomisation and study treatment}

We randomly assigned patients to "active" control of body temperature (intervention) or "usual" temperature management (control) using a secure, centralised, webbased, randomisation interface. The allocation sequence was generated by the study statistician using computergenerated random numbers with variable block randomisation in a 1:1 ratio and stratification by centre. Participants were blinded as to treatment allocation.

In both groups, continuous monitoring of core body temperature was used, while patients were mechanically ventilated. Where the treating clinician did not consider core temperature monitoring appropriate, a tympanic thermometer was the preferred method for measuring temperature. We advised that temporal artery thermometers and axillary thermometers should not be used to monitor body temperature because of concerns about the accuracy of these devices [15]. The occurrence of a temperature $\geq 37.8^{\circ} \mathrm{C}$ triggered investigation for possible new infection and consideration of whether empiric therapy for new sepsis was required. Use of physical cooling was documented hourly in all patients using a worksheet which was completed by the bedside nurse.

\section{Intervention}

In patients assigned to active temperature management, unless contraindicated, one gram of intravenous paracetamol was administered six-hourly as "fever prophylaxis". During periods of deep sedation, when the patient was not responsive to voice, a temperature of $36.5-37^{\circ} \mathrm{C}$ was targeted using simple cooling measures such as removal of clothing and sheets, a sponge or wet towel or fan plus a physical cooling device if necessary to achieve the target temperature. Any physical cooling device that the treating clinician considered appropriate was allowed including cooling blankets, pads and helmets. Shivering was treated aggressively when clinically appropriate using the following hierarchy of treatments: 1 . Administration of an opioid bolus; 2. Increasing of sedation; and, 3. Administration of a bolus of neuromuscular paralysis. Decisions regarding the choice of drugs, doses, frequency, and duration of administration were at the discretion of the treating clinician. Protocol-driven temperature control measures including intravenous paracetamol were discontinued at day 28 or ICU discharge whichever was sooner. Physical cooling could be ceased to allow the patient's sedation to be decreased or stopped at any time at the discretion of the treating clinician but was recommenced if further deep sedation was needed and body temperature was not within the target range of 36.5$37^{\circ} \mathrm{C}$. If treatments to control shivering were considered clinically inappropriate, or shivering could not be controlled, then physical cooling was ceased.

\section{Usual care (control)}

Patients allocated to the control group received usual care as directed by the treating clinician. There were no protocol-defined temperature targets and administration of intravenous paracetamol was discouraged unless there was a specific indication for its use.

\section{Outcome measures}

The primary outcome measure was the mean body temperature calculated from six-hourly recordings taken for up to $168 \mathrm{~h}$ (7 days) from randomisation or until ICU discharge. Secondary outcomes were ICU-free days (the number of days alive and outside ICU from randomisation until day 28); in-hospital mortality; cause-specific mortality; and survival time to day 90 (censored at hospital discharge).

To describe the physiological and biochemical effects of active temperature management, we recorded peak daily body temperature, the proportion of patients with body temperatures of $\geq 38.3{ }^{\circ} \mathrm{C}$ and $\geq 39^{\circ} \mathrm{C}$, respectively $[1,16]$, as well as six-hourly heart rate, respiratory rate and blood pressure, and peak serum creatinine and liver enzyme measures in the first 28 post-randomisation days in the ICU.

Additional variables of interest, which we defined as process of care measures (tertiary outcomes), were ICU and hospital length of stay, ventilator-free days, vasopressor-free days, receipt of renal replacement therapy in ICU, days in receipt of intravenous antibiotics in the ICU, blood cultures performed in the ICU, paracetamol dosing, use of physical cooling, use of neuromuscular paralysis, use of sedative drugs, and use of vasopressor and inotropic drugs. Details of the physiological end points, biochemical end points, and tertiary outcomes are described in the ESM (Table S1 and Table S2).

\section{Statistical analysis}

The statistical analysis plan was reported before enrolment completion [14]. Our sample size of 184 patients provides $90 \%$ power to detect an effect size of $0.3{ }^{\circ} \mathrm{C}$ based on a standard deviation of 0.6 [11] using two tailed hypothesis and an alpha of 0.05 , allowing for a $5 \%$ drop-out rate. Analyses were conducted on an intentionto-treat basis excluding only patients who withdrew consent for use of data. We made no imputation for missing values. 
All data were initially assessed for normality. Treatment group comparisons were performed using Chi-square tests for proportions, Student $t$ test for normally distributed data and Wilcoxon rank sum tests otherwise with results reported as $n$ (\%), mean [standard deviation (SD)] and median [interquartile range (IQR)], respectively. To account for repeat measures, the primary outcome (body temperature) was analysed using mixed linear modelling with each patient treated as a random effect (intercept only) and results reported as least square means (95\% CI). In-hospital mortality and survival time were analysed using logistic regression and Cox-proportional hazards regression, respectively, with results reported as absolute and relative risk differences, odds ratios (95\% $\mathrm{CI}$ ) and hazards ratios (95\% CI). We compared survival times using a log-rank test and present these as KaplanMeier survival curves.

Pre-specified subgroup analysis was performed for patients with known or suspected infection versus all others [7]. Heterogeneity between outcomes and subgroup was determined by fitting an interaction between treatment and subgroup. All analysis was performed using SAS version 9.4 (SAS Institute Inc., Cary, NC, USA) and a two-sided $P$ value of 0.05 was used to indicate statistical significance. No adjustment was made for multiple comparisons. Additional details of statistical analyses are in the ESM.

\section{Results}

\section{Patient characteristics}

From November 2016 through March 2019, we enrolled 184 patients in eight adult medical-surgical ICUs in Australia and New Zealand with 92 patients assigned to active temperature management and 92 patients assigned to usual care (Fig. 1). The median [IQR] recruitment rate was 0.8 [0.4-1.0] patients per site per month. Consent was withdrawn by six patients resulting in an intentionto-treat population of 178 , of whom 89 were assigned to active temperature management and 89 were assigned to usual care. Data for the primary outcome variable were available for the entire intention-to-treat population. The study groups had similar baseline characteristics (Table 1 and Table S3 in the ESM).

\section{Outcomes}

The mean temperature difference between groups was greatest in the first $48 \mathrm{~h}$, when it was generally in the order of $0.5{ }^{\circ} \mathrm{C}$. Irrespective of treatment assignment, fever generally abated within 3 days of randomisation. Despite this, active temperature management did result in a statistically significant reduction in mean body temperature compared with usual temperature management $(P=0.01)$ (Fig. 2) (Table 2). Compared with usual temperature management, those allocated to active temperature management also received more paracetamol and physical cooling (Table 2). The proportion of patients with a temperature of $\geq 38.3{ }^{\circ} \mathrm{C}$ was lower in patients allocated to active temperature management (Table 2). However, the highest daily temperature by treatment group was not statistically significantly different between treatment groups (Fig S1 ESM).

ICU-free days, in-hospital mortality, and survival time (censored at hospital discharge) were not statistically significantly different by treatment group (Table 3, Fig. 3). Cause-specific mortality by treatment group is shown in the ESM (Table S4). Compared with usual care patients, patients allocated to active temperature management had lower heart rate but similar mean arterial pressure and respiratory rate (Fig S2 in the ESM).

One patient from each treatment group had physical cooling ceased because of shivering. Liver enzymes and serum creatinine were not statistically significantly different for patients allocated to active compared to those allocated to usual temperature management (Table S2 in the ESM). There were no statistically significant differences between treatment groups in relation to key process of care measures (Table 3). Use of sedatives, neuromuscular paralysis, and vasoactive drugs was not statistically significantly different by treatment group (Table S6, S7, and S8 in the ESM).

Among patients with suspected infection at baseline, 19 of $76(25 \%)$ who were assigned to active treatment and 16 of $71(22.5 \%)$ who were assigned to usual treatment died prior to hospital discharge by day $90(P=0.73)$. Among patients who did not have suspected infection at baseline, four of 13 (30.8\%) who were assigned to active treatment and six of 18 (33.3\%) who were assigned to usual treatment died prior to hospital discharge by day $90(P=0.88)$. There was no statistically significant interaction between treatment group and presence or absence of baseline infection with respect to body temperature $(P=0.96)$.

\section{Discussion}

In this multicentre randomised clinical trial in febrile critically ill adults without acute brain pathologies, systematic prevention and treatment of fever reduced mean body temperature by about $0.5{ }^{\circ} \mathrm{C}$ compared to usual temperature management. Patients assigned to systematic prevention and treatment of fever received more paracetamol than patients assigned to usual temperature management and had more hours of physical cooling in the ICU. Even among patients assigned to usual temperature management, fever often abated within $24 \mathrm{~h}$ of randomisation. Although patients assigned to systematic prevention and treatment of fever had lower heart 


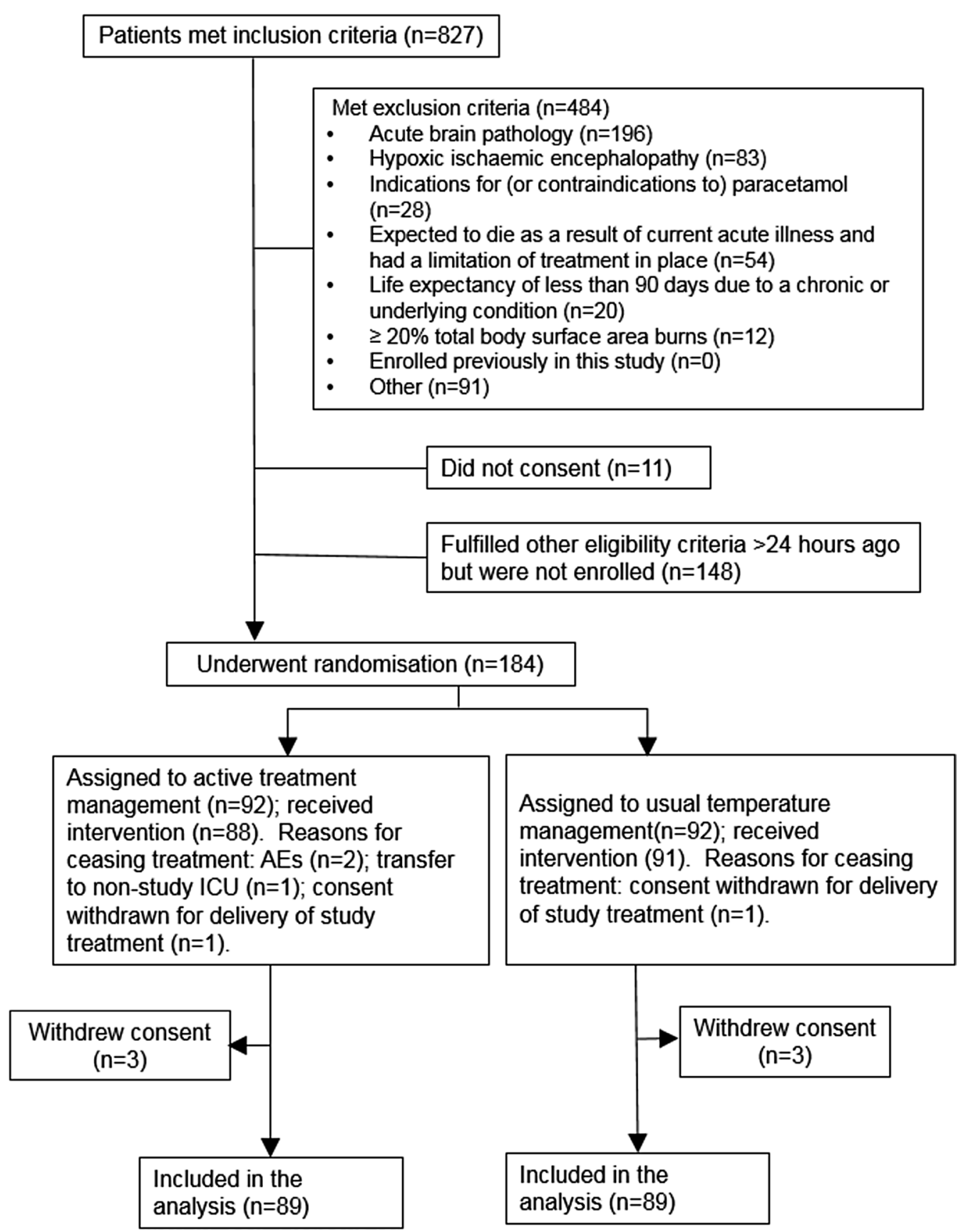

Fig. 1 Screening, randomization, and follow-up. Abbreviation: AE adverse event

rate than patients assigned to usual temperature management, other physiological parameters were similar. Moreover, in hospital mortality, ICU length of stay, hospital length of stay, ICU-free days, ventilator-free days, vasopressor-free days, and receipt of renal replacement therapy were all similar by treatment group.

Our findings are broadly consistent with those of a recently published individual patient data meta-analysis, which reported that active temperature management neither increased nor decreased survival compared with usual temperature management [9]. Our findings are somewhat at variance to the SepsisCool trial where $48 \mathrm{~h}$ of physical cooling to normothermia was reported to decrease both vasopressor requirements and early mortality in mechanically ventilated patients with septic shock [8]. Although our trial was a similar size to the 
Table 1 Characteristics of the patients at baseline

\begin{tabular}{|c|c|c|}
\hline Characteristic & $\begin{array}{l}\text { Active temperature management } \\
(n=89)\end{array}$ & $\begin{array}{l}\text { Usual tempera- } \\
\text { ture manage- } \\
\text { ment } \\
(n=89)\end{array}$ \\
\hline Age-year & $56.9 \pm 15.7$ & $58.4 \pm 15.5$ \\
\hline Male sex-no. (\%) & $55(61.8 \%)$ & $63(70.8 \%)$ \\
\hline \multicolumn{3}{|l|}{ Co-morbid conditions-no. (\%) } \\
\hline Respiratory & $4(4.5 \%)$ & $4(4.5 \%)$ \\
\hline Cardiovascular & $1(1.1 \%)$ & $3(3.4 \%)$ \\
\hline Hepatic & $1(1.1 \%)$ & $0(0 \%)$ \\
\hline Renal & $1(1.1 \%)$ & $1(1.1 \%)$ \\
\hline Immunosuppression by disease & $3(3.4 \%)$ & $3(3.4 \%)$ \\
\hline Immunosuppression by therapy & $6(6.7 \%)$ & $8(9 \%)$ \\
\hline Metastatic cancer & $4(4.5 \%)$ & $6(6.7 \%)$ \\
\hline \multicolumn{3}{|l|}{ Source of admission to ICU—no. (\%) } \\
\hline Emergency department & $25(28.1 \%)$ & $28(31.5 \%)$ \\
\hline Hospital ward* & $19(21.3 \%)$ & $11(12.4 \%)$ \\
\hline Transfer from another ICU & $6(6.7 \%)$ & $4(4.5 \%)$ \\
\hline Transfer from another hospital (except from another ICU) & $6(6.7 \%)$ & $10(11.2 \%)$ \\
\hline From OR following elective surgery & $14(15.7 \%)$ & $16(18 \%)$ \\
\hline From OR following emergency surgery & $19(21.3 \%)$ & $20(22.5 \%)$ \\
\hline APACHE-II score $\dagger$ & $20.5 \pm 7.5$ & $21 \pm 6.9$ \\
\hline \multicolumn{3}{|l|}{ Physiology } \\
\hline Highest temperature in previous $12 \mathrm{~h}$ & $38.6 \pm 0.7$ & $38.6 \pm 0.8$ \\
\hline Last temperature before randomisation & $37.8 \pm 1$ & $37.8 \pm 0.8$ \\
\hline Heart rate—beats per minute & $97.7 \pm 20.5$ & $97.7 \pm 19$ \\
\hline Serum creatinine-median (IQR) & $122[85-187]$ & 128 [92-187] \\
\hline \multicolumn{3}{|l|}{ Baseline therapies } \\
\hline Receiving intravenous antimicrobials for suspected infection—no. (\%) & $76(85.4 \%)$ & $71(79.8 \%)$ \\
\hline Receiving ongoing neuromuscular blockade—no. (\%) & $12(13.5 \%)$ & $11(12.4 \%)$ \\
\hline Total paracetamol dose in $12 \mathrm{~h}$ prior to randomisation—gm, median (IQR) & $1[0-2]$ & $1[0-2]$ \\
\hline Physical cooling device in use & $12(13.5 \%)$ & $7(7.9 \%)$ \\
\hline Renal replacement therapy—no. (\%) & $8(9 \%)$ & $7(7.9 \%)$ \\
\hline
\end{tabular}

Plus-minus values are expressed as mean $\pm S D$

APACHE acute physiology and chronic health evaluation, ICU intensive care unit; OR operating room

* There were no statistically significant differences in baseline characteristics between groups

† Scores on the APACHE-II range from 0 to 71, with higher scores indicating more severe disease and a higher risk of death

SepsisCool trial, it differed in a number of respects. In the SepsisCool trial, mechanically ventilated patients with septic shock who were sedated were assigned to external cooling or no external cooling for $48 \mathrm{~h} \mathrm{[8].} \mathrm{Whereas,} \mathrm{in}$ our trial, in patients assigned to systematic prevention and treatment of fever, we sought to prevent and treat fever until deep sedation was no longer required using a combination of regular intravenous paracetamol plus physical cooling when necessary. In patients assigned to usual temperature management in our trial, physical cooling measures and paracetamol were allowed when considered clinically necessary. We did not only enrol febrile patients with septic shock, but instead enrolled sedated ventilated patients without acute brain pathologies who had current or recent fever and were anticipated to require prolonged ventilation. The degree of temperature separation between groups that we observed was less than seen in the SepsisCool study [8]. Finally, in our study, physical cooling was used in more than half of the patients assigned to usual care and body temperatures were lower than those seen in the control arm of the SepsisCool study [8].

The recruitment rate achieved in this feasibility study was lower than we anticipated it would be. Although we 


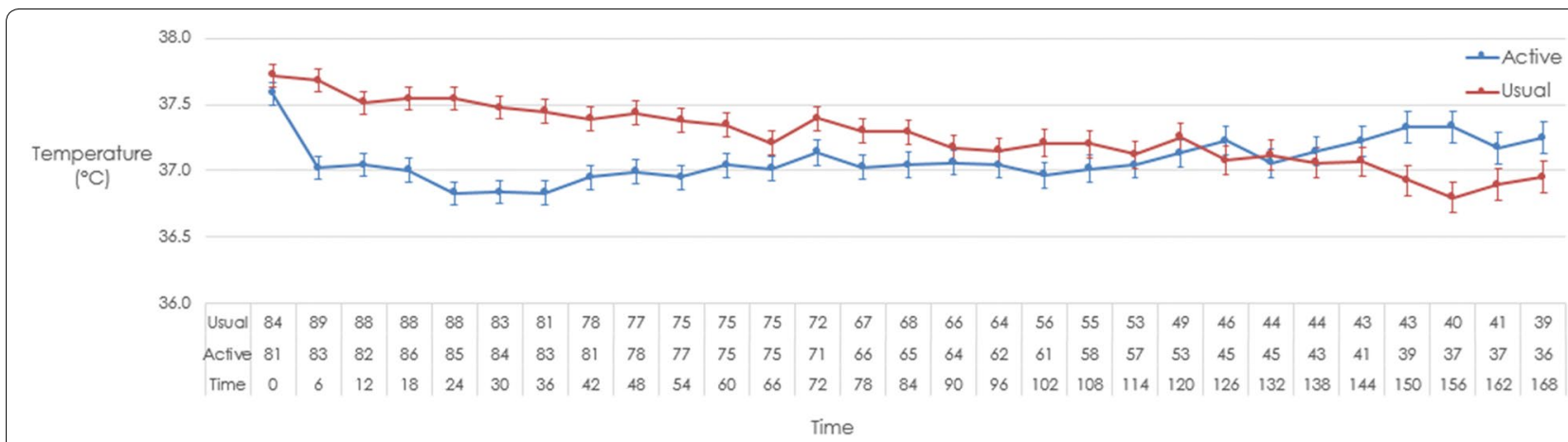

Fig. 2 Mean daily body temperature by treatment group*. *The number of patients contributing data for each measurement is shown on the horizontal axis along with the study day and time. Error bars and standard error bars. $P$ value for between treatment group comparison, 0.01 . Abbreviation: $D$ day

Table 2 Temperature control

\begin{tabular}{|c|c|c|c|c|}
\hline & $\begin{array}{l}\text { Active temperature } \\
\text { management } \\
(n=89)\end{array}$ & $\begin{array}{l}\text { Usual temperature } \\
\text { management } \\
(n=89)\end{array}$ & $\begin{array}{l}\text { Estimate* } \\
(95 \% \mathrm{Cl})\end{array}$ & $P$ value \\
\hline \multicolumn{3}{|l|}{ Paracetamol use } & \multicolumn{2}{|l|}{ Differences in medians ${ }^{\dagger}$} \\
\hline Total given in ICU—gm; median [IQR] & $21[13-34]$ & $11[3-19]$ & $11(7-15)$ & $<0.001$ \\
\hline Total given IV—gm; median [IQR] & 19 [12-29] & $0[0-2]$ & $19(15-20)$ & $<0.001$ \\
\hline Daily dose—gm & $3 \pm 0.7$ & $1.3 \pm 1$ & $\begin{array}{l}\text { Mean difference } \\
1.6(1.4-1.9)\end{array}$ & $<0.001$ \\
\hline \multicolumn{5}{|l|}{ Physical cooling } \\
\hline Receiving physical cooling ${ }^{\ddagger}$ —no. (\%) & $61(68.5 \%)$ & $48(54.5 \%)$ & $\begin{array}{l}\text { Odds ratio (unadjusted) } \\
1.82(0.98-3.35)\end{array}$ & 0.06 \\
\hline Hours of physical cooling post-randomisation—median [IQR] & $10[0-44]$ & $1[0-17.5]$ & $\begin{array}{l}\text { Differences in medians }{ }^{\dagger} \\
2(0-7)\end{array}$ & 0.01 \\
\hline $\begin{array}{l}\text { Hours of physical cooling post-randomisation for those patients } \\
\text { who received physical cooling-median [IQR] }\end{array}$ & $28[8-58]$ & $16[4-47]$ & $\mathrm{n} / \mathrm{a}$ & 0.09 \\
\hline \multicolumn{5}{|l|}{ Fever } \\
\hline Highest body temperature $-{ }^{\circ} \mathrm{C}$ & $38.5 \pm 0.7$ & $38.9 \pm 0.9$ & $\begin{array}{l}\text { Mean difference } \\
-0.4(-0.6 \text { to }-0.1)\end{array}$ & 0.002 \\
\hline Body temperature $\geq 38.3^{\circ} \mathrm{C}-$ no. (\%) & $57(64 \%)$ & $70(78.7 \%)$ & $\begin{array}{l}\text { Odds ratio } \\
0.48(0.25-0.94)\end{array}$ & 0.03 \\
\hline Body temperature $\geq 39^{\circ} \mathrm{C}-$ no. (\%) & $26(29.2 \%)$ & $38(42.7 \%)$ & $0.55(0.30-1.03)$ & 0.06 \\
\hline
\end{tabular}

$C l$ confidence interval, IQR interquartile range, $n / a$ not applicable

* The widths of the confidence intervals for secondary analyses have not been adjusted for multiplicity and the intervals should not be used to infer definite differences between the groups. Adjusted estimates account for baseline temperature, age and APACHE-II score

${ }^{\dagger}$ Hodges-Lehmann estimate of absolute difference for Active minus Usual. The Hodges-Lehmann estimate is the median of all paired differences between observations in the two samples

‡ Data were available to 88 patients in the usual temperature management group

did observe statistically significant separation of temperature by treatment group, the observed difference in temperature was small and physical cooling was used frequently in patients assigned to usual care. We submit that the high degree of use of physical cooling in usual practice combined with the observation that fever generally abated rapidly irrespective of treatment assignment suggests that in the patient population we studied, a strategy to actively treat fever has low biological plausibility to improve patient outcomes when compared with a usual care strategy.

Our trial has some limitations. Although we discouraged the use of axillary thermometers and temporal artery thermometers, we did not standardise devices used to measure temperature. Having a usual care control arm, as opposed to a more heavily protocolised one, 
Table 3 Secondary and Tertiary Outcomes

\begin{tabular}{|c|c|c|c|c|}
\hline & $\begin{array}{l}\text { Active temperature } \\
\text { management } \\
(n=89)\end{array}$ & $\begin{array}{l}\text { Usual temperature } \\
\text { management } \\
(n=89)\end{array}$ & $\begin{array}{l}\text { Estimate* } \\
(95 \% \mathrm{Cl})\end{array}$ & $P$ value \\
\hline \multicolumn{5}{|l|}{ Secondary outcomes } \\
\hline \multirow[t]{2}{*}{$\mathrm{ICU}$-free days—mean \pm SD } & $14 \pm 10.6$ & $13.7 \pm 10.5$ & Mean difference & \\
\hline & & & $0.2(-2.9$ to 3.3$)$ & 0.89 \\
\hline \multirow[t]{4}{*}{ In-hospital mortality—no. (\%) } & $23(25.8 \%)$ & $23(25.8 \%)$ & Odds ratio (unadjusted) ${ }^{\dagger}$ & \\
\hline & & & $1(0.51-1.96)$ & 1 \\
\hline & & & Odds ratio (adjusted) & \\
\hline & & & $1.21(0.57-2.55)$ & 0.62 \\
\hline \multirow[t]{4}{*}{ Day 90 mortality—no. $(\%)^{\S}$} & $23(25.8 \%)$ & $22(24.7 \%)$ & Odds ratio (unadjusted) ${ }^{\dagger}$ & \\
\hline & & & $1.06(0.54-2.09)$ & 1 \\
\hline & & & Odds ratio (adjusted) & \\
\hline & & & $1.25(0.58-2.71)$ & 0.60 \\
\hline \multicolumn{5}{|l|}{ Key tertiary outcomes } \\
\hline \multicolumn{2}{|l|}{ ICU LOS—median [IQR] } & & Differences in medians ${ }^{\ddagger}$ & \\
\hline Overall & $5.6[3.2-12.1]$ & $5.8[3.6-14.9]$ & $-0.2(-1.9$ to 1.1$)$ & 0.66 \\
\hline Survivors & $6.7[4.6-16.2]$ & $8.4[4.4-19]$ & $-0.9(-3$ to 1$)$ & 0.36 \\
\hline Non-survivors & $7.4[2.8-12.1]$ & $5.8[2.7-10.4]$ & $0.9(-3$ to 5.3$)$ & 0.57 \\
\hline \multicolumn{2}{|l|}{ Hospital LOS—median [IQR] } & & Differences in medians ${ }^{\ddagger}$ & \\
\hline Overall & $16.4[8.22-28.5]$ & $15[8-31.1]$ & $-0.2(-4.2$ to 3.8$)$ & 0.97 \\
\hline Survivors & $22.7[10.6-32.8]$ & $20.7[12.1-32.3]$ & $0.4(-4.2$ to 5.1$)$ & 0.86 \\
\hline Non-survivors & $7[3.1-14.8]$ & $6.4[2.4-25.7]$ & $-0.1(-4.7$ to 4$)$ & 0.97 \\
\hline \multirow[t]{2}{*}{ Ventilator-free days-Median (IQR) } & $22.1[0.6-25.9]$ & $20.3[0-25.9]$ & Differences in medians ${ }^{\ddagger}$ & \\
\hline & & & $0(-0.8$ to 1.2$)$ & 0.86 \\
\hline \multirow[t]{2}{*}{ Vasopressor-free days-median (IQR) } & 25 & 25.7 & Difference in medians ${ }^{\ddagger}$ & \\
\hline & [16.5-27.1] & [12.7-27] & $0(-0.8$ to 0.6$)$ & 0.94 \\
\hline \multirow[t]{2}{*}{ New post-randomisation RRT in ICU—no. (\%) } & $18(20.2 \%)$ & $27(30.3 \%)$ & Odds ratio & \\
\hline & & & $0.58(0.29-1.16)$ & 0.12 \\
\hline \multirow[t]{2}{*}{ Days in receipt of antibiotics in ICU—-median (IQR) } & $6[3-10]$ & $6[4-12]$ & Difference in medians ${ }^{\ddagger}$ & 0.46 \\
\hline & & & $-1(-2$ to 1$)$ & \\
\hline \multirow[t]{2}{*}{ Sets of blood cultures performed in ICU—median [IQR] } & $2[0-3]$ & $2[0-5]$ & Difference in medians ${ }^{\ddagger}$ & 0.94 \\
\hline & & & $0(-1$ to 1$)$ & \\
\hline
\end{tabular}

IQR interquartile range, $C l$ confidence interval, $R R T$ renal replacement therapy

* The widths of the confidence intervals for secondary analyses have not been adjusted for multiplicity and the intervals should not be used to infer definite differences between the groups. Adjusted estimates account for baseline temperature, age and APACHE-II score

+ Adjusted for age, gender, site, and APACHE-II score

₹ Hodges-Lehmann estimate of absolute difference for active minus usual temperature management. The Hodges-Lehmann estimate is the median of all paired differences between observations in the two samples

$\S$ Day 90 mortality was censored at hospital discharge

may have contributed to the relatively small separation in body temperature by treatment group that we observed. Protocolising the control arm to mandate a more permissive approach to fever management would be expected to result in greater temperature separation between groups and could potentially elucidate whether or not such an approach caused benefit or harm. However, we chose not to do this because we considered that preventing clinicians from treating fevers that they would always treat in usual practice would reduce the external validity of our results by creating a problem of "practice misalignment" whereby neither arm of the study resembled usual care [17]. We anticipated that our eligibility criteria would capture a population of patients with a considerable burden of fever; however, by the time of randomisation, fever had already resolved in some patients. Our study was relatively small and lacked power to detect differences between treatment groups in patient-important end points like mortality. Consequently, the absence of difference in such end points may reflect type 2 error. We also 


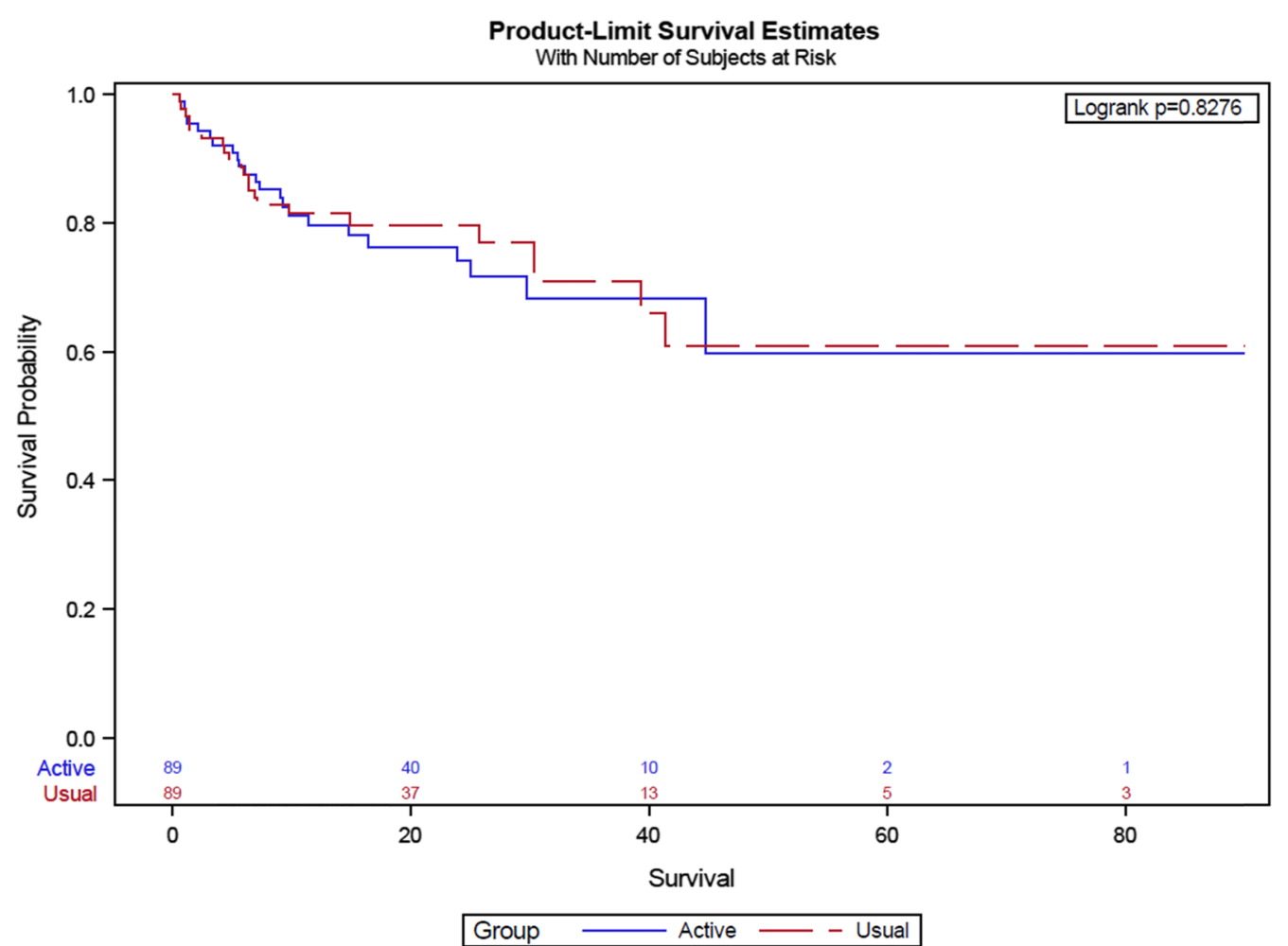

Fig. 3 Survival by Treatment Group* * Hazard ratio for active temperature management versus usual temperature management $1.15(95 \% \mathrm{Cl}$ 0.64-2.08); adjusted $P$ value, 0.63 (adjusted for baseline temperature, age, APACHE-II score, and site). Abbreviations: AE adverse event, APACHE acute physiology and chronic health evaluation

had limited power to detect subgroup effects. Because around $80 \%$ of the patients in our study were receiving antimicrobials for a known or suspected infection at baseline, our findings may not apply to patients without infections.

\section{Conclusions}

Our findings do not provide strong support for a larger clinical trial using this design in this patient population. However, they do provide preliminary data supporting the safety of regular administration of intravenous paracetamol to critically ill patients.

\section{Electronic supplementary material}

The online version of this article (https://doi.org/10.1007/s00134-019-05729-4) contains supplementary material, which is available to authorized users.

\section{Author details}

${ }^{1}$ Intensive Care Unit, Wellington Regional Hospital, Wellington, New Zealand.

${ }^{2}$ Medical Research Institute of New Zealand, Wellington, New Zealand.

${ }^{3}$ Australian and New Zealand Intensive Care Research Centre, School of Public Health and Preventive Medicine, Monash University, Melbourne, Australia.

${ }^{4}$ Critical Care Division, The George Institute for Global Health, University of New South Wales, Sydney, NSW, Australia. ${ }^{5}$ Malcolm Fisher Department of Intensive Care, Royal North Shore Hospital, St Leonards, NSW, Australia. ${ }^{6}$ Intensive Care Unit, Hawke's Bay Hospital, Hastings, New Zealand. ${ }^{7}$ Intensive Care Unit, The Canberra Hospital, Canberra, ACT, Australia. ${ }^{8}$ School of Medicine, Australian National University, Canberra, ACT, Australia. ${ }^{9}$ Faculty of Health, University of Canberra, Canberra, ACT, Australia. ${ }^{10}$ Intensive Care Unit, Christchurch Hospital, Christchurch, New Zealand. ${ }^{11}$ Department of Critical Care Medicine, Auckland City Hospital, Auckland, New Zealand. ${ }^{12}$ Cardiothoracic and Vascular Intensive Care Unit, Auckland City Hospital, Auckland, New Zealand. ${ }^{13}$ Intensive Care Unit, Bankstown Hospital, Sydney, NSW, Australia. ${ }^{14}$ Intensive Care Unit, Royal Perth Hospital, Perth, WA, Australia. ${ }^{15}$ School of Medicine and Pharmacology, University of Western Australia, Crawley, WA Australia. ${ }^{16}$ Intensive Care Unit, Austin Hospital, Melbourne, VIC, Australia.

\section{Funding}

The REACTOR study was endorsed by the Australian and New Zealand Intensive Care Society Clinical Trials Group and funded by the Health Research Council of New Zealand (16/488). The study was coordinated by the Medical Research Institute of New Zealand in New Zealand and the George Institute for Global Health in Australia. The Medical Research Institute of New Zealand is supported by Independent Research Organisation funding by the Health Research Council of New Zealand. All analyses were undertaken independent of the funder.

\section{Publisher's Note}

Springer Nature remains neutral with regard to jurisdictional claims in published maps and institutional affiliations.

Received: 8 July 2019 Accepted: 2 August 2019

Published online: 1 October 2019 


\section{References}

1. Laupland KB, Shahpori R, Kirkpatrick AW, Ross T, Gregson DB, Stelfox HT (2008) Occurrence and outcome of fever in critically ill adults. Crit Care Med 36:1531-1535

2. Laupland KB, Zahar JR, Adrie C, Schwebel C, Goldgran-Toledano D, Azoulay E, Garrouste-Orgeas M, Cohen Y, Jamali S, Souweine B, Darmon M, Timsit JF (2012) Determinants of temperature abnormalities and influence on outcome of critical illness. Crit Care Med 40:145-151

3. Niven DJ, Stelfox HT, Shahpori R, Laupland KB (2013) Fever in adult ICUs: an interrupted time series analysis. Crit Care Med 41:1863-1869

4. Horvath SM, Spurr GB, Hutt BK, Hamilton LH (1956) Metabolic cost of shivering. J Appl Physiol 8:595-602

5. Golding R, Taylor D, Gardner H, Wilkinson JN (2016) Targeted temperature management in intensive care: do we let nature take its course? J Intensive Care Soc 17:154-159

6. Manthous CA, Hall JB, Olson D, Singh M, Chatila W, Pohlman A, Kushner R, Schmidt GA, Wood LD (1995) Effect of cooling on oxygen consumption in febrile critically ill patients. Am J Respir Crit Care Med 151:10-14

7. Young PJ, Saxena M, Beasley R, Bellomo R, Bailey M, Pilcher D, Finfer S, Harrison D, Myburgh J, Rowan K (2012) Early peak temperature and mortality in critically ill patients with or without infection. Intensive Care Med 38:437-444

8. Schortgen F, Clabault K, Katsahian S, Devaquet J, Mercat A, Deye N, Dellamonica J, Bouadma L, Cook F, Beji O, Brun-Buisson C, Lemaire F, Brochard L (2012) Fever control using external cooling in septic shock: a randomized controlled trial. Am J Respir Crit Care Med 185:1088-1095

9. Young PJ, Bellomo R, Bernard GR, Niven DJ, Schortgen F, Saxena M, Beasley R, Weatherall M (2019) Fever control in critically ill adults. An individual patient data meta-analysis of randomised controlled trials. Intensive Care Med 45:468-476

10. Saxena MK, Hammond NE, Taylor C, Young P, Reade MC, Bellomo R, Myburgh J (2011) A survey of fever management for febrile intensive care patients without neurological injury. Crit Care 13:238-243
11. Young P, Saxena M, Bellomo R, Freebairn R, Hammond N, van Haren F, Holliday M, Henderson S, Mackle D, McArthur C, McGuinness S, Myburgh J, Weatherall M, Webb S, Beasley R, Investigators H, Australian, New Zealand Intensive Care Society Clinical Trials G (2015) Acetaminophen for fever in critically ill patients with suspected infection. N Engl J Med 373:2215-2224

12. Bernard GR, Wheeler AP, Russell JA, Schein R, Summer WR, Steinberg KP, Fulkerson WJ, Wright PE, Christman BW, Dupont WD, Higgins SB, Swindell BB (1997) The effects of ibuprofen on the physiology and survival of patients with sepsis. The Ibuprofen in Sepsis Study Group. N Engl J Med 336:912-918

13. Young PJ, Nielsen N, Saxena M (2018) Fever control. Intensive Care Med 44:227-230

14. Young PJ, Bailey MJ, Beasley RW, Freebairn RC, Hammond NE, Haren FM, Harward ML, Henderson SJ, Mackle DM, McArthur CJ, McGuinness SP, Myburgh JA, Saxena MK, Turner A, Webb SA, Bellomo R, The ACTG (2017) Protocol and statistical analysis plan for the randomised evaluation of active control of temperature versus ordinary temperature management (REACTOR) trial. Crit Care Resusc 19:81-87

15. Niven DJ, Gaudet JE, Laupland KB, Mrklas KJ, Roberts DJ, Stelfox HT (2015) Accuracy of peripheral thermometers for estimating temperature: a systematic review and meta-analysis. Ann Intern Med 163:768-777

16. O'Grady NP, Barie PS, Bartlett JG, Bleck T, Carroll K, Kalil AC, Linden P, Maki DG, Nierman D, Pasculle W, Masur H, American College of Critical Care M, Infectious Diseases Society of A (2008) Guidelines for evaluation of new fever in critically ill adult patients: 2008 update from the American College of Critical Care Medicine and the Infectious Diseases Society of America. Crit Care Med 36:1330-1349

17. Deans KJ, Minneci PC, Danner RL, Eichacker PQ, Natanson C (2010) Practice misalignments in randomized controlled trials: identification, impact, and potential solutions. Anesth Analg 111:444-450 